\title{
Assessment of Ecological Environment Quality in Kolkata Urban Agglomeration, India
}

Sukamal Maity

Narajole Raj College

Subhasis Das

Narajole Raj College

Jhumarani Maity Pattanayak

Guru Ghasidas Vishwavidyalaya

Biswajit Bera

Sidho-Kanho-Birsha University

Pravat Kumar Shit ( $\sim$ pravatgeo2007@gmail.com )

Raja N.L.Khan Womens College (Autonomous) https://orcid.org/0000-0001-5834-0495

\section{Research Article}

Keywords: Remote sensing, Ecological index, Principal component analysis, Spatial autocorrelation, Kolkata

Posted Date: November 11th, 2021

DOl: https://doi.org/10.21203/rs.3.rs-897464/v1

License: (c) (i) This work is licensed under a Creative Commons Attribution 4.0 International License. Read Full License

Version of Record: A version of this preprint was published at Urban Ecosystems on March 1st, 2022. See the published version at https://doi.org/10.1007/s11252-022-01220-z. 
1 Assessment of Ecological Environment Quality in Kolkata Urban Agglomeration, India

3 Sukamal Maity ${ }^{1}$; Subhasis Das ${ }^{1,2}$; Jhumarani Maity Pattanayak ${ }^{3}$; Biswajit Bera ${ }^{4}$ and Pravat Kumar 4 Shit $^{2}$

5

6 Sukamal Maity

$7 \quad{ }^{1}$ Department of Geography, Narajole Raj College, West Bengal, India

8 Email: $\underline{\text { msukamal@gmail.com (S.Maity) }}$

9

Subhasis Das

$11{ }^{1}$ Department of Geography, Narajole Raj College, West Bengal, India

12 Email: subhasisdas4592@gmail.com (S.Das)

${ }^{2}$ PG Department of Geography, Raja N.L.Khan Womens College (autonomous), Gope Palace, Midnapore-721102, West Bengal, India

\section{Jhumarani Maity Pattanayak}

$17{ }^{3}$ Department of Geography, Guru Ghasidas Vishwavidyalaya, Bilaspur (C.G.), India

18 Email: jhumaranimaitypattanayak@gmail.com (J.M. Pattanayak)

19

20

21

\section{Biswajit Bera}

${ }^{4}$ Department of Geography, Sidho Kanho Birsha University,Purulia, India Email: biswajitbera007@gmail.com (B.Bera)

\section{Pravat Kumar Shit}

${ }^{2}$ PG Department of Geography, Raja N. L. Khan Women's College (Autonomous), Gope Palace, Midnapore-721102, West Bengal, India

Orcid ID: 0000-0001-5834-0495

Email: pravatgeo2007@gmail.com (P.K.Shit)

Corresponding Author: Email: pravatgeo2007@gmail.com (P.K.Shit) 


\title{
Assessment of Ecological Environment Quality in Kolkata Urban Agglomeration, India
}

\begin{abstract}
The global ecosystem has been significantly disrupted on various spatiotemporal scales over the last three decades due to human activities. Geospatial technology can quickly, effectively, and quantitatively to evaluate the spatiotemporal change of eco-environmental quality (EEQ). The present study is focused on novel approach of Remote Sensing based Ecological Index (RSEI), using Landsat Imagery data to assess environmental conditions and changes pattern. Four ecological indicators were prepared in the year 1990, 2000, 2010 and 2020 of Kolkata urban agglomeration (KUA) to evaluate the ecological environmental condition. The principal component analysis (PCA) and spatial autocorrelation analysis can relate all indicators with each other's and RSEI. Out study indicated, greenness and wetness have a positive effect on EEQ of the province, but both dryness and heat have a negative effect. However, it should be noted that greenness has a greater impact on the eco-environment than the other three indicators. Based on the RSEI values, we have categorized the environmental standards of the study area into four groups - very good $(0.81-1.00)$, good $(0.61-0.80)$, acceptable $(0.41-0.60)$, poor $(0.21-0.40)$, and very poor $(0.00-0.20)$, where high values indicate that environmental quality is stable and healthy for living organisms and low values indicate relatively unstable and threatening conditions of the environment. The status of RSEI showed that $9.02 \%, 12.29 \%, 12.79 \%$ and $37.23 \%$ of an area was under poor to very poor condition in the year of 1990, 2000, 2010 and 2020 respectively. Good to very good condition of RSEI values was increased from $19.12 \%$ to $34.074 \%$ during 1990 to 2010, but declined of RSEI value $9.47 \%$ during 2010 to 2020 due to urban expansion. Here, Moran's I values fund that 0.265, 0.543, 0.396 and 0.367 in the year 1990, 2000, 2010 and 2020 respectively. The result of Moran's I values indicate that clustering nature. The present study can helpful for the decision making of ecological management guided by planners and policy makers.
\end{abstract}

Keywords: Remote sensing; Ecological index; Principal component analysis; Spatial autocorrelation; Kolkata

\section{Introduction}

Ongoing rapid acceleration of urbanization and industrialization has amplified ecological and environmental complications (Aronson et al., 2014; Li et al., 2012), land use land cover (LULC) pattern (Gao et al., 2017) and loss of natural capitals (Huang and Zhao, 2016). Such changes transformed natural ecosystem to man-made ecosystem, which destroy the ecosystem structure, functions and energy flows (Shao et al., 2017; Wang et al., 2017). In recent times, most of the world's ecosystems are confronted by multiple anthropogenic threats and consequential environmental disparity more than ever before (McDonnell et al., 2016). With the advancement of human civilization, the development of human activity has impact on expansion of built-up land, as a result, the natural ecosystem is being significantly disrupted at various spatiotemporal scales (Williams, et al., 2009). Disruption of large-scale ecosystems and its significant impact on the universal carbon cycle (Baldocchi, et al., 2008) have been reflected with various magnitudes and it also intensifies global climate change (Hanqiu Xu, et al., 2019). The intensity, magnitudes, durations and frequency of human-induced environmental disturbances are displayed at different 
rates in different ranges in terms of duration (Levin, et al., 1992) and it should be monitored and quantified respectively. In this situation, the environmental sustainability and regulatory capacity are under great threats leads to degradation of EEQ.

The Remote Sensing based Environmental Index (RSEI) is a newly developed aggregate indicator that can quickly detect changes in the ecological conditions of a province over time using only remotely perceived data and Landsat datasets at the pixel level. Eco-Environmental quality (EEQ) assessment plays an important role in considering the contribution of inadequate ecological standards and many other environmental factors for complex urban characterization as well as the evaluation of an ecosystem. Adopting the benefit of the same data source for all indices of EEQ assessment, RSEI is shown as different spatiotemporal scales, visible and comparable, and it can avoid changes or errors in the definition of weight due to individual characteristics. For this reason, RSEI plays an important role in the EEQ assessment of any complex urban area and it recognized for its use in assessing the status of urban ecological environment, by incorporating natural environmental factors like- greenery, humidity, dryness, and heat. Researchers will be tasked with providing better advice to relevant policymakers on the formulation of environmental protection measures. Therefore, the reliability of such assessments can be improved based on RSEI approach, where the impact of RSEI indicators on the ecoenvironment has been tested and considered.

The rapid growth of urbanization as well as industrialization in Kolkata urban agglomeration (KUA) converting vegetation, wetland, and agricultural land to built-up land. The Vegetative and wetland ecosystem transformation has negative impact on different dimensions like biodiversity loss, safe water crisis, urban heat islands and micro climate change (Walter Leal Filho, et al., 2021). At present, it is need to bring out EEQ in KUA. The advancement of RS technology and geographic information systems (GIS), rapid and real-time monitoring of large surface area ecosystem, ecological services and the spatiotemporal status of ecosystems are possible (Qie, et al., 2017; Willis, et al., 2015; Yunqig, et al., 2020). Various methodologies were involving in the assessment of EEQ, such as - index for rapid assessment (IRA), EEQ status index (EI), remote sensing based ecological index (RESI). Ghetti (2007) proposed IRA method for Mediterranean environment based on the Rhodophyceae and Chlorophyceae ratio. The EI method was proposed by the Ministry of Environmental Protection of China in 2016 based on widely applicable biological abundance index, plant cover index, water network density, land degradation and environmental quality index (Zhu et al., 2017; Chenget al., 2008; Li et al., 2013). Scholars have encountered many difficulties in the practical application and specification (Ye et al., 2009). However, RSEI was based on RS information technology that quantitatively evaluates environmental quality at variations scalewhich was provides more accurate results (Xu and Tang, 2013; Lin and Pan, 2014). It can able to quickly monitor as well as assess environmental quality for study areas that have specific practical significance with high reliability. However, the present study assess spatiotemporal changes of eco-environment quality by computer-based ecological index (RESI) using remote sensing techniques.

\section{Study Area}

The KUA is also identified as the Kolkata Metropolitan Area (KMA), also known as the largest urban area in eastern India and the third-largest city in India has 14.72 million population with a population density of 7950 persons per sq. kilometres according to the 2011 Census. It has annual population growth rate was $1.8 \%$ in between $2001-2011$ and population would be projected to rise 20 million and 21.1 million in the year 2021 and 2025 respectively (Census of 
India 2011; KMDA 2011). The study area covers an area of over 1851.41 sq.km extended in between $22^{\circ} 0^{\prime} 19^{\prime \prime} \mathrm{N}$ to $23^{\circ} 0^{\prime} 01^{\prime \prime} \mathrm{N}$ Latitudes and $88^{\circ} 0^{\prime} 04^{\prime \prime}$ E to $88^{\circ} 0^{\prime} 33^{\prime \prime}$ E Longitudes (Fig. 1). The region in discussible is a communicative linear urban prototype in the lower Gangetic delta along both the east and west banks of River Hooghly, known as lifelines of South Bengal. The agglomeration is spreading by a ring-shaped rural vegetated hinterland that acts as a green belt around the municipalities and municipal corporations (MCs) (KMC, 2015). The 3 MCs namely Kolkata, Howrah, and Chandannagar, 38 municipalities, 77 Census Towns (CT), 16 outgrowths and 445-gram panchayats (Rural village) exists in KUA that represents a complex set of administrative entities. Analysis of land use of KUA has revealed the rate of vegetation decline ranging from $33.6 \%$ (1980) to $7.36 \%$ (2010). In 2010, the built-up area of Kolkata urban area was $8.6 \%$, water bodies were $3.15 \%$, while other sections were $80.87 \%$ (Ramachandraet al., 2014). The economic development of the KUA has been accelerated by a large influx of population as well as the transformation of many agricultural lands into impenetrable built-up areas. Therefore, it can be said that KUA is a suitable study area for assessing and predicting EEQ.

\section{Materials and methods}

\subsection{Data sources and pre-processing}

This current study uses four Landsat images (Landsat TM and Landsat OLI / TIRS) downloaded from the U.S. Geological Survey (USGS, http://earthexplorer.usgs.gov) (table 1). The paths/rows of those satellite images were 138/44 and 138/45. For the farther application, the data were preprocessed with the help of ERDAS imagine 14 software. During pre-processing of the dataset, the grey value of the multispectral band or digital number (DN), conversion of the reflective values of the sensor, Fast Line-of-sight Atmospheric Analysis of Spectral Hyper-cubes (FLAASH) etc. are visible and close to each episode of the satellite image as atmospheric correction of infrared bands is essential (Goward et al., 2002; Xu et al., 2013; Kilic et al., 2016; Song et al., 2016). In the present study, images of different periods were modified using 0.5 pixels in the nearest pixel method with two polynomial and root mean square error (RMSE), and finally, the part clipped in the remote sensing image was included within the boundaries of the study area.

\subsection{Calculation of the remote sensing-based ecological index (RSEI)}

The present paper, four indicators of RSEI, namely- greenness, humidity, dryness, and heat, have been included that can reflect on environmental quality, which in turn are closely related to human survival. People can be perceived directly and above all that are used to assess EEQ (Gupta et al., 2012; Yunping et al., 2020). Furthermore, the RSEI is composed of the above four indicators through the Thematic Remote Sensing Indexes; it has represented as:

$$
R E S I=f(N D V I, W E T, N D S I, L S T) \ldots \ldots \ldots \ldots \ldots \ldots Q .1
$$

Where, RESI denotes remote sensing ecological, function of four indicator- NDVI signifiesgreenness, WET represents wetness, NDSI is represented by dryness, LST refers heat.

\subsubsection{Normalized differential vegetation index (NDVI)}

Vegetation is the valuable subtle or delicate significant indicator for determining the EEQ at regional level. Greenness refers to the Normalized Difference Vegetation Index (NDVI) and it reflect the measurement of biomass, leaf area index (LAI), vegetation coverage, vegetation bioshield mass estimation, vegetation health and leading ecosystem proxy variables in any region 
167 (Rouse et al., 1973; De Araujo Barbosa et al.,2015; Madurapperuma, B.D., et al., 2017).

168 Furthermore, modern researchers recommend that NDVI is more sensitive and low-density vegetation in the urban landscape, which is suitable for high-density built-up lands. (Wang et al., 2015; Liu et al., 2017). The determination of NDVI is needed for analysing the proportion of vegetation $(\mathrm{Pv})$ and emissivity $(\mathcal{E})$ of any region. After the conversion of the digital numbers (DN) to reflectance, the NDVI is expressed by using the following equation proposed by Rouse, J.W. et al., 1973; Tuckeret al., 1979; Jeevalakshmiet al., 2016; Giannini et al., 2015; Hanqiuet al., 2019:

$$
N D V I=\left(\rho_{\text {NIR }}-\rho_{R E D}\right) /\left(\rho_{\text {NIR }}+\rho_{R E D}\right) \ldots \ldots \ldots \ldots \ldots . \ldots Q .2
$$

Where, NIR and Red represent the DN values from the Near Infrared band $5(0.85-0.88 \mu \mathrm{m})$ and red band $4(0.64-0.67 \mu \mathrm{m})$ of Landsat 8 (OLI / TIRS) image, respectively, and Near Infrared band 4 and red band 3 of Landsat TM image. The value of NDVI is basically between - 1.0 and +1.0 , where negative values indicate waterlogging (water bodies) and snow cover while positive values greater than 0.5 indicate dense vegetation cover (Ozelkan, E. et al., 2005; Mohammad Zare et al., 2019).

\subsubsection{Wetness (WET)}

The Tasseled Cap Transformation (TCT) is a technique commonly or extensively used in land cover mapping as well as ecological monitoring studies specifically for brightness, greenness and wetness (depending on coefficient used) of the physical aspects of the earth's surface (Zawadzki et al., 2016; Yunqing et al., 2020). It converts the original orthogonal multispectral data into a new axis set related to physical significance (Baig et al., 2014). TCT also represents soil moisture for the purpose of understanding the significant properties of soil and plant moisture (Kauth et al., 1976; Huang et al., 2002). The researchers (Crist, 1985; Goward et al., 2002; Huang et al., 2002 Baig et al., 2014; Quanlong et al., 2015) were used to calculate the moisture content of Landsat-5 TM:

$$
W_{E T} T_{T M}=0.1446_{\rho \text { Blue }}+0.1761_{\rho \text { Green }}+0.3322_{\rho N I R}+0.3396_{\rho S W I R 1}-0.6210_{\rho S W I R 2} \ldots \ldots \ldots \ldots . . . .3
$$

Where, $\rho$ Blue, $\rho$ Green, $\rho$ Red, $\rho N I R, \rho S W I R 1$, and $\rho S W I R 2$ are the corresponding surface reflectance bans of Blue (Band 1), Green (Band 2), Red (Band 3), Near Infrared (NIR, Band 4), short-wave infrared 1 (SWIR1, Band 5), and short-wave infrared 2 (SWIR2, Band 7) bands of the TM, respectively. The same procedure was applied to calculate the moisture content of Landsat-8 OLI / TIRS satellite image using the equation given by Baig et al., 2014; Yunqing et al., 2020:

$$
W_{\text {ETOLI }}=0.1511_{\rho \operatorname{Re} d}+0.1972_{\rho \text { Blue }}+0.3283_{\rho \text { Green }}+0.3407_{\rho N I R}+0.7117_{\rho \text { SWIR } 1}+0.4559_{\rho S W I R 2} \ldots
$$

Where, $\rho$ Blue, $\rho$ Green, $\rho$ Red, $\rho N I R, \rho S W I R 1$, and $\rho S W I R 2$ are the corresponding surface reflectance bans of Blue, Green, Red, NIR, SWIR1, and SWIR2 bands in the OLI / TIRS respectively.

\subsubsection{Normalized difference soil index (NDSI)}


The NDSI denotes a dry index proxy (Xu et al. 2017; Li et al., 2020) which is the average of the sum of equation no. 6 of the Soil Index (SI) and equation no. 7 of the Index-based built-up index (IBI). The equation is given in below:

$$
\begin{aligned}
& N D S I=(S I+I B I) / 2 \ldots \ldots \ldots \ldots \ldots \ldots \ldots . .5 Q .5 \\
& S I=\left\{\left(\rho_{\text {SWIR } 1}+\rho_{\operatorname{Re} d}\right)-\left(\rho_{\text {Blue }}+\rho_{\text {NIR }}\right)\right\} /\left\{\left(\rho_{\text {SWIR } 1}+\rho_{\text {Re } d}\right)+\left(\rho_{\text {Blue }}+\rho_{\text {NIR }}\right)\right\} \ldots \ldots \ldots . . . E Q .6
\end{aligned}
$$

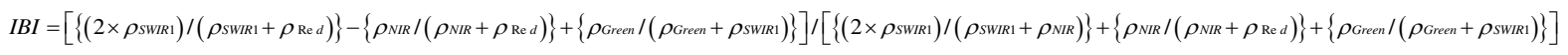

$$
\begin{aligned}
& \text { EQ.7 }
\end{aligned}
$$

Where, $\rho$ Blue, $\rho$ Green, $\rho$ Red, $\rho N I R$, and $\rho S W I R 1$ are the corresponding surface reflectance bans of Blue, Green, Red, NIR, and SWIR1 bands in the TM and OLI / TIRS sensors, respectively.

\subsubsection{Land surface temperature (LST)}

LST is a proxy for the heat index obtained by a single-channel algorithm (Xu et al., 2017; Jimenez-Munoz et al., 2009). The ideal method for retrieving LST from a raw Landsat dataset is to convert the TIRS band and TM bands (Bands 10 and 11 in Landsat 8; Band 6 in Landsat 5) from the DN value to the Satellite spectral radioactivity value (Lג) (Chander et al., 2009; Xu et al., 2009; USGS, 2016b; Mohammad Zare, et al., 2019). Which is calculated using Satellite Brightness Temperature (BT), assumption of unity emissivity $(\varepsilon)$, and Pre-Launch Calibration Constants (Chander et al., 2009; Xu et al., 2009; USGS, 2016b). In this present study, we used the thermal band 6 of Landsat 5 and the thermal bands 10 and 11 of Landsat 8 to restore the satellite spectral radioactivity values of the dates mentioned. And L $\lambda, B$, $\varepsilon$, and LST are calculated according to these references by converting the DN value of the TIRS and OLI / TIRS bands to spectral brightness and top of atmosphere (TOA) planetary reflection ( $X u$ et al., 2009; Estoque et al., 2017), the equations used to convert from a satellite temperature to ground surface temperature as well as from DNA to radioactivity are as follows (USGS. Landsat 8 Data users Handbook, 2016):

$$
L_{\lambda}=M_{L} \times Q_{c a l}+A_{L} \ldots \ldots \ldots . . . E Q .8
$$

Where, $\mathrm{L}_{\lambda}$ denote the spectral radiation (Watts/ $\left(\mathrm{m}^{2 *} \mathrm{sr}^{*} \mu \mathrm{m}\right)$ ), $\mathrm{M}_{\mathrm{L}}$ denote the Band specific multiplicative rescaling factor from the metadata, (RADIANCE_MULT_BAND_n), Where ' $\mathrm{n}$ ' denotes the band number. (10 or 11 for Landsat 8 and 6 for TM), $Q_{c a l}=$ Level 1 value in $\mathrm{DN}$ or Corresponds to band $10 \& 11$, and $\mathrm{A}_{\mathrm{L}}$ is Band specific additive rescaling factor from the metadata, (RADIANCE_ADD_BAND_n), Where ' $n$ ' is the band Number 10 or 11 (OLI /TIRS) and $6(\mathrm{TM})$. The conversion of TIRS data from spectral radiance to brightness temperature $\left(\mathrm{BT}_{\mathrm{i}}\right)$ occurs according to the following equation:

$$
B T_{i}=\left\{\left(K_{2} / I_{n}\right) \times\left(K_{1} / L_{\lambda}\right)+1\right\}-273.15\left(\operatorname{in}^{\circ} C\right) \ldots \ldots \ldots . . E Q .9
$$

Where, $\mathrm{BT}_{i}$ is top of atmospheric (TOA) brightness temperature in Kelvin or Degree Celsius for TIRS band $i$ (is $10 \& 11$ for TIRS and 6 for TM), $\mathrm{K}_{1}=$ Band specific coefficients are thermal conversion constant from the metadata. (K_CONSTANT_BAND_n), Where ' $n$ ' is the band Number 10 or 11 for Landsat -8 and 6 for TM (Table 2), K2 = Band specific thermal conversion constant from the metadata. (K2_CONSTANT_BAND_n), Where ' $n$ ' is the band Number (10 \& 11 for Landsat 8 and 6 for TM). The result of this process is the temperature in Celsius, and the radiant temperature is the absolute zero temperature is about $-273.15^{\circ} \mathrm{C}$. 
The same method was implemented for the Band 11, from the equation we can get Band 10 radiance and Band 11 Radiance as an output.

$\mathrm{Pv}$ has been calculated with the help of NDVI value obtained from Equation No.2. This shows the approximate area under each land cover type. The amount of surface vegetation and empty soil from NDVI of clear pixels is known (Zahir, I.L.M., 2020). The values of NDVIv and NDVIs are 0.5 and 0.2 , respectively, for high-resolution data in cultivated fields, the value of NDVIv can reach between $0.8-0.9$ (Wang, F., et al., 2015). The ratio of mixed pixels to plants is determined using the following equation (Zahir, I.L. M., 2020):

$$
P V=\left(\frac{N D V I-N D V I_{\text {min imum }}}{N D V I_{\text {max imит }}-N D V I_{\text {min imum }}}\right)^{2} \ldots \ldots \ldots . E Q .10
$$

Where, Pvis the Proportion of Vegetation, NDVI is the DN values from NDVI Image, NDVI minimum and maximum value is minimum and maximum DN values from NDVI Image, respectively.

LST largely depends on the roughness of the surface, the nature of the vegetation, and so on (Javed Mallick et al., 2008). This is the average emissivity $(\mathcal{E})$ of a component of the Earth's surface calculated from the NDVI value. Van de Griend and Owe (1993) were proposed the calculation formula of average emissivity $(\mathcal{E})$ that can mentioned in below:

$$
\varepsilon=0.004 \times P_{V}+0.986 \ldots \ldots \ldots . E Q .11
$$

When, NDVI < 0 thenEis 1 (the emissivity in water body is close to 1). Plant coverage is very low when the value of NDVI is $0-0.157$ and $\varepsilon$ is 0.92 (Qin et al., 2004).

LST is the radiactive temperature used to calculate the TOA brightness temperature (BT), and the emitted radiance wavelength, which is calculated using the following equations (Orhan and Yakar, 2016):

$$
L S T=\left[B T_{i} / /\left\{1+(\lambda \times B T) / C_{2}\right\}\right] \times I_{n}(\varepsilon) \ldots \ldots \ldots . . . E Q .12
$$

Where, BT is TOA brightness temperature $\left({ }^{\circ} \mathrm{C}\right), \lambda=$ Wavelength of emitted radiance (Table 2), $\mathrm{C}_{2}=\mathrm{h} * \mathrm{c} / \mathrm{s}=14387.685 \mu \mathrm{m} \mathrm{K} ; \mathrm{h}=$ Planck's constant $=6.626 * 10^{-34} \mathrm{Js} ; \mathrm{s}=$ Boltzmann constant $=1.38 * 10^{-23} \mathrm{~J} / \mathrm{k} ; \mathrm{c}=$ Velocity of light $=2.998 * 10 \mathrm{~m} / \mathrm{s}$.

\subsubsection{Establishment of RSEI}

Instead of the conventional heavy aggregation method, RSEI is calculated by integrating four indicators (f) through Principal Component Analysis (PCA). The data range and units of the four indices are different that were normalized in between 0 to 1 through the PCA. Therefore, innovative ecological indicators are obtained on the basis of the results of PCA transformations (Li et al., 2015; Hanqiu et al., 2019; Yunqing et al., 2020). This can usually be expressed as the following equation:

$$
R E S I_{0}=P C A[f(N D V I, W E T, N D S I, L S T)] \ldots \ldots \ldots \ldots E .13
$$

Where, PCA is a spatial principal component strategy. RSEI values are again normalized from 0 to 1 , so that 1 can be compared to very good EEQ and 0 indicates extremely poor EEQ (Xu, 2013b, Hanqiu et al., 2019, Yunqing et al., 2020). Normalized RSEI values are divided into five levels, such as Level 1 (0 -0.2): Very Poor, Level 2 (02. -0.4): Poor, Level 3 (0.4 -0.6): 
Acceptable, Level 4 (0.6 -0.8): Good and Level 5 (0.8 - 1): Very good (Xu, 2013b; Xu et al., 2018; Yue et al., 2019; Hanqiu et al., 2019; Yunqing et al., 2020) (Table 5).

\subsection{Spatial auto-correlation analysis}

The spatial auto-correlation analysis ahs two parts- Global Spatial Autocorrelation (Global Moran's I Index) and the Local Indicator of Spatial Autocorrelation (LISA) used to explore spatial correlations of EEQ. It tested whether the indicator's attribute value of an element is significantly related to the attribute value of its neighbouring areas, which exhibits the correlation of attribute eigenvalue between the spatial reference unit and its neighbouring space unit.

\subsubsection{Global spatial auto-correlation (Moran's I index)}

The Global Moran's I coefficient reveals a pattern of interrelationships between the attribute's values of the properties of the spatial neighbouring unit, i.e. evaluates whether it is clustered, scattered, or random. Whose absolute value is about 1 , and the spatial auto-correlation of the unit is stronger. This indicator has been used to verify the spatial relationship of an element in the present study area, the diagnostic equation is as follows (Gong et al., 2014; Jonathan et al., 2020; Yunqing et al., 2020):

$$
I=\frac{\sum_{i}^{n} \sum_{j \neq i}^{n} W_{i j}\left(X_{i}-\bar{X}\right)\left(X_{j}-\bar{X}\right)}{S^{2} \sum_{i}^{n} \sum_{j \neq i}^{n} W_{i j}} \quad \ldots \ldots \ldots \ldots E .14
$$

Where, $x i$ is the attribute value of the neighbouring space (i); $\mathrm{n}$ is the total number of grids in the area; $\bar{x}$ is the average of the $x_{i}$ over the $n$ space; Wijis the weight of the matrix; $i=1,2,3 \ldots, n, j=1$, $2,3 \ldots, \mathrm{m}$. when $\mathrm{i}$ and $\mathrm{j}$ are neighbouring, $W_{i j} 0$. This indicator exact ranges from +1 to -1 , where $+1,0$ and -1 means positive spatial autocorrelation i.e. opposite of dispersion, nonexistence of spatial auto-correlation i.e. perfect randomness, and negative autocorrelation i.e. perfect dispersion, respectively(Cliff and Ord, 1981; Yan, 2014).

\subsubsection{Local Indicators of Spatial Autocorrelation Index (LISA index)}

It can effectively reflect a local spatial association by analysing the values of Global Moran's I in terms of the correlation of neighbourhood values around a particular spatial location (Gong et al., 2014). It again determines the amount of spatial non-stationery and clustering that exists in the data, i.e. it makes important analyses about the LISA. It can also analyse is there any spatial heterogeneity when global spatial autocorrelation exists. The equation for determining which is as follows (Anselin, 1995; Gong et al., 2014):

$$
I=\frac{X_{i}-\bar{X}}{S_{i}^{2}} \sum_{j=1, i \neq j}^{N} w_{i j}\left(x_{j}-\bar{x}\right) \ldots \ldots \ldots \ldots . . .16
$$




$$
S_{i}^{2}=\frac{\sum_{j=1, i \neq j}^{N} W_{i j}}{n-1}-\bar{X}^{2} \ldots \ldots \ldots E Q .17
$$

where, $\mathrm{I}_{\mathrm{i}}$ is spatial clustering of similar values i.e. high or low values around the local unit, negative $\mathrm{I}_{\mathrm{i}}$ is the spatial clustering between dissimilar values, $x_{i}$ is an attribute for $i, \bar{x}$ is the mean ofcorresponding attribute, $w_{i, j}$ is the spatial weight between $i$ and $j, n$ equating to the total number of features.

\section{Results \\ 4.1 Combination of the indicators}

The quantification of EEQ assessment is guided through scientific procedures and computation of index. Therefore, the bands of satellite images are integrated to produce normalized indexes i.e., greenness, wetness, dryness and heat (Fig. 2), which were used to get the result of PCA (Table 3).

Table 3 showed that the contribution rates of the four main indicators of the first principal component (PC1) reached nearly 54.36\%, 56.22\%, 53.36\%, and 69.40\% during the four decades of 1990, 2000, 2010, and 2020, respectively. The other three indexes other than LST were relatively stable during the period observed, meaning that most of the features of the four indices were concentrated in the first principal component. Here PCA1 state that the NDVI (from 1990 2020), WET (from 1990 - 2020), NDSI (in the year 1990) and LST (in the year 1990) values are positive and NDSI and LST values negative in the year 2000, 2010 and 2020. The positive valuesindicate a positive role and the negative values indicating a negative role in relation to EEQ. The values of other major components such as PC2, PC3, and PC4 are unstable, which makes it difficult to explain the eco-environmental nature of the region in question. For that reason, we have formulated RESI by integrating four indicators through PC1 in the present study area.

We have evaluated the correlation between RSEI and the four indicators i.e. greenness, humidity, dryness, and heat, for a comprehensive representation of the RSEI model in Figure 3, which represents the correlation between themselves and correlation between each corresponding indicator with RSEI. The figure shows that in 1990 the correlation between humidity and heat with dryness and humidity with heat again was good, the values were $-0.97,0.63$, and -0.59 , respectively, and the correlation of each index with RSEI was good, i.e.0.67, $-0.89,0.86$, and 0.68 ; Similarly, in 2000, the correlation between humidity and heat with dryness was -0.94 and 0.59 , respectively, as well as the correlation between greenness and heat with RSEI, which was 0.95 and -0.68 , respectively.

We noticed that, the correlation between humidity and heat with dryness was good in 2010, at 0.95 and 0.56 , respectively. And in the year 2020 the correlation between humidity and heat with dryness and humidity with heat was good; which are $-0.81,0.52$ and -0.63 respectively. The correlation between RSI and green has been good over the last two decades, with a value of 1.0 in both cases. Wetlands are an important source of water in any place, which is affected by the 
exchange of heat and water vapour around the river (Hugli River) and other water bodies, and its absence or degradation can reduce its capacity and EEQ. In the city of Calcutta in discussible, carbon contamination, dust, and floating dust in the atmosphere, as well as smoke, often create a smog breeze, which is detrimental to plant growth. In conclusion, the effect of humidity on the EEQ of the study area is significant. Therefore, more attention should go to protecting wetland sites and vegetation cover in KUA.

\subsection{Assessment of eco-environmental quality in the study area}

In addition to comparing the EEQ of the region in discussible, the quality of the four indicators for assessment has also been normalized. Table 4 analyses the EEQ of the KUA for the years 1990, 2000, 2010, and 2020 on the basis of the average values of RESI and the four indicators, as shown in Figure 4.

Table 4 showed that average RESI values of KUA in 1990, 2000, 2010 and 2020 are respectively $0.520,0.607,0.558$ and 0.437 . The mean NDVI value was improved during 1990 to $2000(0.449$ to 0.627 ) due increase of greenness, after that it was decreased very fast in between 2000 to 2020 (0.627 to 0.455 ). The mean WET value was 0.935 (in the year 1990), 0.853 (in the year 2000), 0.815 (in the year 2010) and 0.769 (in the year 2020), trends to decreasing that occur due to shrinkage of wetland area. The mean NDSI value state that it was increasing trend in between 1990 to 2010 ( 0.423 to 0.497$)$ but it was decreased very fast $(0.324)$ in the last decade. The mean LST values were declining from 0.216 to 0.473 in between 1990 to 2020 . Table 4 showed the details description of the mean and SD values of RESI and respective four indicators.

Overall, EEQ was increased in between 1990-2000 but decreased from 2000 to 2020 period. In that period (1990-2000) greenness increases, this leads to decline in heat and resultant to improvement of RESI. After 2000 due to continuous decreasing trend in greenness, wetlands and increasing heat trends to deterioration of EEQ. As shown in Figure 4, the value of upper quartile, mean and lower quartile of RSEI in the study area in 2020 is lower than in 1990, indicating a declining trend of RSEI from 1990 to 2020, which means the EEQ of the study area, is being slowly declining.

\subsection{Spatiotemporal changes of eco-environmental quality}

After formulating the RESI, we categorized the RESI scores into the following five distinct categories e.g. Very Good (0.81- 1.00), Good (0.61- 0.80), Acceptable (0.41- 0.60), Poor (0.21$0.40)$, and Very Poor (0.00 - 0.20). This classification is described in Table 5, which shows a high standard of EEQ quality for living organisms in the environment indicates stable and healthy, and on the other hand, a low value indicates a relatively unstable and threatening state.Figure5 showed the spatiotemporal distribution of RSEI, indicate that EEQ was slight improved in theBaruipur, Singur, Srirampur Uttarpara municipality area in between 1990-2000 but after that in was decreased. Overall, EEQ degradation was spreading from Kolkata MC to surrounding municipal areas from the study period. The result of RSEI status shown that $9.02 \%, 12.29 \%$, $12.79 \%$ and $37.23 \%$ of area was under poor and very poor status of RSEI respectively in the year 1990, 2000, 2010 and 2020 and good to very good condition of RSEI area was continuously decreased $19.12 \%, 30.33 \%, 34.074 \%$ and $9.47 \%$ respectively in the year 1990, 2000, 2010 and 2020. The description of the status of RSEI classes has been given respectively in Table 6 .

\subsection{Change detection of RSEI}


Figure 6 shows that the EEQ has improved slightly in 2020 in the study area that had the worst conditions in 1990. For such results in the field of the present study area can be largely attributed mainly to the policies adopted and implemented at the state and national levels, where emphasis has been placed on the conservation of cultivated lands, forests and wetlands instead of industrialization and urbanization with emphasis on EEQ degradation. Human activities have reduced forest and wetland resources restoration. There for EEQ has degraded in 03 municipal corporation, 38 municipalities, and 77 Census towns (CT) of the study area in 2020. The human activates in this study area has great impact on eco-environment and become more friable as antieco-environmental threat has sensitive impact on mankind. This blind economic development disturbs sustainable development and permanent welfare of environment (Wang et al., 2016; Yunqing et al., 2020).

\section{Discussion}

\subsection{Impact of urbanization on ecological environmental quality}

The urbanization in KUA has historical perspective. However, in the study period, we found rapid increase in population as well as built-up land. According to census of India data the population growth rate was 66\% (during 1991-2011), 55.41\% (during 1991-2001) and 6.81\% (during 2001-2011). It has showed that in between 1991-2001 rapid population growth was occurred but after that its started to declining population growth. Sahana et al. (2018) investigated that built-up land was increased by $45.14 \%$ during 1990-2015 period. The process of urbanization was linked with ecosystem transformation and degradation. The changes of natural ecosystem to man-made ecosystem effects on the EEQ in KUA. Our analysis also investigated that EEQ also deteriorated during that the observed period.

\subsection{Spatial auto - correlation analysis}

\subsubsection{Global spatial auto-correlation of RESI}

The Moran scatter plots for 1990, 2000, 2010 and 2020 (Fig. 7) indicate fluctuations trend when compared to their previous time period. The values of Moran's I in 1990, 2000, 2010 and 2020 were $0.265,0.543,0.396$ and 0.367 , respectively, which are relatively low except 2000 . The findings show that the distribution pattern of the RSEI in the study region has obvious clustering, indicating a clear positive correlation. The Moran's I of RSEI was increased from 1990-2000 but declined from 2000-2020 which indicated that the clustering nature of the RSEIdeclining slowly.

\subsubsection{Local spatial auto-correlation of RESI}

The LISA index and LISA cluster map shown for KUA in Figure 8 subconsciously reflect the spatial distribution of high-high (HH), low-low (LL), low-high (LH), and high-low (HL). Where, $\mathrm{HH}$ areas are mainly concentrated in the vicinity of water bodies, LL zones were distributed in the built-up landand peripheral areas of the study landscape. The HL zones were distributed randomly and some were concentrated near LL zones, showing that transitional landscape processes were already operative. The HL tracts were mainly concentred near the HH zones and their values have gradually increased.

Figure 9 shows that the high-High region basically expanded to significant levels of 0.05 in 2000 and 2010, and a significant level of 0.01 is mainly located in the low-low and high-high regions, which has revealed a strong correlation to the EEQ. On the other hand, the significant level of 0.05 is mainly located along the perimeter of the main urban area where the significant level of 
0.01 has expanded. Similarly, the high-High region has basically expanded to significant levels of 0.01 in 2000 and 2010.

\subsection{Policy implementation}

Adequate sampling points in the study area and precise methods of analysis can ensure objectivity as well as the representativeness of the results of regression analysis, and at the same time avoid uncertain results associated with local sampling. Figure 10 analyses the step-by-step regression of greenness, humidity, dryness, and heat as independent variables with the dependent variable RSEI. The following are the regression models that all extended the level of significance to $99 \%$ of the study area:

$$
\begin{aligned}
& R E S I_{1990}=0.062 \otimes N D V I-0.194 \otimes W E T+0.508 \otimes N D S I+0.381 \otimes L S T+0.108\left(R^{2}=1\right) \\
& R E S I_{2000}=0.832 \otimes N D V I+0.013 \otimes W E T-0.181 \otimes N D S I-0.369 \otimes L S T+0.235\left(R^{2}=1\right) \\
& R E S I_{2010}=0.996 \otimes N D V I-0.102 \otimes W E T+0.101 \otimes N D S I-0.030 \otimes L S T+0.075\left(R^{2}=1\right) \\
& R E S I_{2020}=0.940 \otimes N D V I-0.007 \otimes W E T-0.225 \otimes N D S I+0.047 \otimes L S T+0.066\left(R^{2}=1\right)
\end{aligned}
$$

The study on EEQ is the four retained indicators whose results are relatively reliable. As can be seen from the respective variable coefficients, among them, only the coefficients of NDVI are positive in all study years and had a positive impact on the eco-environment evaluation results, while the remaining indicators i.e., WET, NDSI and LST are fluctuated year by year, and which had fluctuated negative and positive effects on EEQ, which is consistent with the results of the PCA1. The coefficient sum of positive indicators NDVI is larger and has greater impact compare to WET, NDSI, and LST.

Fig.10. 3D scatter plots of different indicators of RSEI in KUA

The effect of greenness in the study area is greater than that of humidity, dryness, and heat, which means that greenness has a greater effect on the study area than other indices. The authors found that the EEQ of KUA was poor, and the vegetation was less. Therefore, the key to improving the EEQ of the study area is to prevent the Ganga River delta region and protect the wetland.

\section{Conclusion}

In the current study, degradation of EEQ in the KUA was major concern of the present study due to shrinkage of wetlands, green space and rapid urbanization. The study determined the following outcomes as given below:

1) The paper used Landsat 5 Thematic Mapper (TM) and Landsat 8 operational land imager (OLI / TIRS) data for the extraction of greenness, wetness, heat, and dryness, which integrated to produce remote sensing ecological index in KUA. The greenness and wetness in the study area and the dryness and heat showed a positive and negative effect on EEQ, respectively. The green space among the four indices has had a major impact on the quality of the EEQ in the study area.

2) The result of the present study illustrates that $9.02 \%$ of area residing under poor to very poor category of EEQ in 1990 was increased to $37.23 \%$ in 2020. On the opposite good to very good condition of EEQ was continuously decreasing from $19.12 \%$ to $9.47 \%$ in between $1990-2020$.

3) The values of Moran's I were $0.265,0.543,0.396$ and 0.367 , respectively in the year 1990, 2000, 2010 and 2020, which was relatively low except 2000. The findings show 
that the distribution pattern of the RSEI in the study region has obvious clustering, indicating a clear positive correlation. The Moran's I of RSEI was increased from 19902000 but declined from 2000-2020 which indicated that the clustering nature of the RSEI declining slowly.

4) We prepare LISA Cluster map by diving area into four groups- High-Highs (HH), LowLow (LL), Low-High (LH) and High-Low (HL). It found that water body areas have HH category, represent significant correlation with EEQ. And the LL zones were distributed in the built-up land and peripheral areas of the study landscape. The HL zones were distributed randomly and some were concentrated near LL zones, showing that transitional landscape processes were already operative. The HL tracts were mainly concentered near the $\mathrm{HH}$ zones and their values have gradually increased.

The indicators for the present study precisely described the ecological environmental quality will further improve by adding subsequent research. The researchers need to consider economic, social, and culture indicator for the setting development goals of ecological environmental quality. The present study can contribute for the decision making of ecological management guided by planners and policy makers.

\section{Acknowledgement}

The authors show their kind acknowledgment to the Dept. of Geography, Raja N. L. Khan Women's College (Autonomous), and Department of Geology \& Geophysics, Indian Institute of Technology (IIT), Kharagpur, West Bengal, India for their laboratory facilities and kind encouragement.

\section{Funding}

This research was supported by the Department of Geography, Raja N. L. Khan Women's College (Autonomous), affiliated to Vidyasagar University, Midnapore, West Bengal, India. The author (P. K. Shit) grateful acknowledges West Bengal DSTBT for financial support through R\&D Research Project Memo no. 104(Sanc.)/ST/P/S\&T/ 10G-5/2018).

\section{Contributions}

S.Maity - conceptualized and planned the study and reviewed and edited the manuscript. S. Das conducted the survey, analyzed the data, prepared the maps and interpreted the results. J.M. Pattanayak - analyzed the data, and interpreted the results. B.Bera - supervised the study and reviewed and edited the manuscript. P.K.Shit - reviewed and edited the manuscript. All authors have read and approved the final manuscript. 
519

520

521

522

523

524

525

526

527

528

529

530

531

532

533

534

535

536

537

538

539

540

541

542

543

544

545

546

547

Ethic declarations

\section{Competing interests}

The authors declare that they have no competing interests.

\section{Ethics approval and consent to participate}

Not applicable

\section{Consent for publication}

Not applicable

\section{Data availability}

The datasets used and analyzed during the current study are available from the corresponding author on reasonable request.

\section{References}

Bardhan,R., Debnath, R.,Bandopadhyay, S., 2016. A conceptual model for identifying the risk susceptibility of urban green spaces using geo-spatial techniques. Model. Earth Syst. Environ. $2: 144$

Chang, Z.B., Qin, F., 2017, Dynamic evaluation of eco-environmental quality in He'nan province based on RS and GIS. Water Soil Conserv Bull 037.004(2017):132-137.

Cheng, J.N., Zhao, G.X., Li, H., Tang, X.M., 2008. Assessment of land ecological environment based on RS and GIS and its dynamic changes. Trans. Chin. Soc. Agric. Eng. 24, 83-88.

Coutts, A.M.; Harris, R.J.; Phan, T.; Livesley, S.J.; Williams, N.S.G.; Tapper, N.J.,2016. Thermal infrared remote sensing of urban heat: Hotspots, vegetation, and an assessment of techniques for use in urban planning. Remote Sens. Environ. 186, 637-651.

Cui J, Zang SW., 2013. Ecological environment effect of land use change in Hadaqi industrial corridor. Geogr Res 2:848-856.

D. Li, S.Wu, Z. Liang, and S. Li., 2020.The impacts of urbanization and climate change on urban vegetation dynamics in China," Urban Forestry Urban Greening, vol. 54, Art. No. 126764.

D. Liu and S. Hao., 2017. Ecosystem health assessment at county scale using the pressure-stateresponse framework on the Loess Plateau, China. International Journal of Environmental Research and Public Health, vol. 14, no. 1, 2. 
De Araujo Barbosa, C.C.; Atkinson, P.M.; Dearing, J.A., 2015. Remote sensing of ecosystem services: A systematic review. Ecol. Indic. 52, 430-443.

Du, X., Huang, Z., 2017. Ecological and environmental effects of land use change in rapid urbanization: the case of Hangzhou, China. Ecol. Indic. 8:243-251.

Foody, G.M., 2007. Editorial: ecological applications of remote sensing and GIS. Ecol. Inform. 2, 7172.

Filho, Walter Leal, et al., 2021. Addressing the Urban Heat Islands Effect: A Cross-Country Assessment of the Role of Green Infrastructure, Sustainability, 13, 753.

Ghetti, P.F., 2007. Rapid Quality Index (R-MaQI), based mainly on macrophyte associations, to assess the ecological status of Mediterranean transitional environments. Chem. Ecol. 23, 493503.

H. Pei, S. Fang, L. Lin, Z. Qin, and X. Wang, 2015. Methods and applications for ecological vulnerability evaluation in a hyper-arid oasis: a case study of the Turpan Oasis, China," Environmental Earth Sciences, vol. 74, no. 2, pp. 1449-1461.

H. Yue, Y. Liu, Y. Li, and Y. Lu, 2019. Eco-environmental quality assessment in China's 35 major cities based on remote sensing ecological index," IEEE Access, vol. 7, 51295-51311.

Han, Z., Song, W., Deng, X.Z., 2019. Grassland ecosystem responses to climate change and human activities within the Three-River Headwaters region of China. Sci. Rep. 8.

Hanqiu Xu., Yifan W., Huade G., Tingting S., Xisheng H., 2019. Detecting Ecological Changes with a Remote Sensing Based Ecological Index (RSEI) Produced Time Series and Change Vector Analysis. Remote Sensing. 11, 2345.

$\mathrm{Hu} \mathrm{X}, \mathrm{Xu} \mathrm{H}, 2018$. A new remote sensing index for assessing the spatial heterogeneity in urban ecological quality: A case from Fuzhou City, China. Ecological Indicators 89:11-21.

Huang, C., Wylie, B., Yang, L., Homer, C., Zylstra, G., 2002. Derivation of a Tasselled Cap transformation based on Landsat 7 at-satellite reflectance. Int. J. Remote Sens. 23 (8), 17411748 .

Huang, G.; Cadenasso, M.L., 2016. People, landscape, and urban heat island: Dynamics among neighborhood social conditions, land cover and surface temperatures. Landsc. Ecol. 31, 25072515.

Huimin, Z., Wenquan, X., Shuqin, L., Qian, Z., 2019. Urban environment construction based on remote sensing ecological index. Ekoloji 28(108):1583-1588. 
Ivits, E., Cherlet, M., Mehl, W., Sommer, S., 2009. Estimating the ecological status and change of riparian zones in Andalusia assessed by multi-temporal AVHHR datasets. Ecol. Ind. 9, 422431.

Ju, W.M., Ping, G., Wang, J., 2010. Combining an ecological model with remote sensing and GIS techniques to monitor soil water content of croplands with a monsoon climate. Agric. Water Manage. 97, 1221-1231.

Kerr, J.T., Ostrovsky, M., 2003. From space to species: ecological applications for remote sensing. Trends Ecol. Evol. 18, 299-305.

Khan, A., Chatterjee, S., 2016. Numerical simulation of urban heat island intensity under urbansuburban surface and reference site in Kolkata, India. Model. Earth Syst. Environ. 2:71.

Kuang W, Yang T, Yan F., 2018. Regional urban land-cover characteristics and ecological regulation during the construction of Xiong'an New District, Hebei Province, China. Journal of Geographical Sciences, 28(1):109-123.

Li QY, Wang ZX, Cui J., 2018. Study on RSEI classification of Eco-environmental quality index of Aksu city based on TM data. Tianjin AgricSci 24(67-71):90.

Li, N., Wang, J., Qin, F., 2020. The improvement of ecological environment index model RSEI. Arabian Journal of Geosciences. 13:403.

Lin Liu and Yuanzhi Zhang, 2011. Urban Heat Island Analysis Using the Landsat TM Data and ASTER Data: A Case Study in Hong Kong. Remote Sensing. 3, 1535-1552.

Lin, W., Pan, W.B., 2014. Research on ecological environment assessment of urban areas in Putian City. Environ. Sci. Manage. 39, 179-183.

M. Reisi, M. AhmadiNadoushan, L. Aye, 2019. Remote sensing for urban heat and cool islands evaluation in semi-arid areas. Global J. Environ. Sci. Mangae. 5(3):319-330.

Malekmohammadi, B., Blouchi, L.R., 2014. Ecological risk assessment of wetland ecosystems using Multi Criteria Decision Making and Geographic Information System. Ecol. Ind. 41, 133-144.

Md Amir All Gazi, IsmallMondal., 2018. Urban Heat Island and its effect on Dweller of Kolkata Metropolitan area using Geospatial Techniques. IJCSE. Vlo.-6, Issue-10.741-753.

Mengshi, X., Xiaonan L., Xiyan, Y., Shanghong, Z., 2020. Ecological Environment Evaluation of ForestEcosystem Nature Reserves Using an UnweightedCloud Model. Water. 12(7), 1-18.

Nath B, Acharjee S., 2013. Urban Municipal Growth and Land useChange Monitoring Using High Resolution Satellite Imageriesand Secondary Data a Geospatial Study on KolkataMunicipalCorporation, India. Stud SurvMappSci 1(3):43-54 
P. Du, J. Xia, Q. Du, Y. Luo, and K. Tan., 2013.Evaluation of the spatiotemporal pattern of urban ecological security using remote sensing and GIS. International Journal of Remote Sensing, vol. 34 , no. 3, 848-863.

Paul, R. K., Patra, P., 2020. Spatiotemporal Transformation of Urban Built-Up Areas for Sustainable Environmental Management in Selected Cities of West Bengal.Habitat, Ecology and Ekistics. 147-161.

Qin, Z.H., Li, W.J., Xu, B., Zhang, W.C., 2004. Estimation of surface radiance parameters required for inversion of surface temperature using Landsat TM 6. Proc. Mar. Sci. 22, 129-137.

Rouse, J.W.; Haas, R.H.; Schell, J.A.; Deering, D.W. Monitoring vegetation systems in the Great Plains with ERTS. In Proceedings of the Third ERTS Symposium, NASA SP-351, Washington, DC, USA, 10-14 December 1973, 309-317.

Sahana, M., Hong, H., Sajjad, H., 2018. Analysing urban spatial patterns and trend of urban growth670 using urban sprawl matrix: A study on Kolkata urban agglomeration, India. Science of the Total Environment. 628 - 629, 1557 - 1566.

Sharma, R., Chakraborty, A., Joshi, P. K.., 2015. Geospatial quantification and analysis of environmental changes in urbanizing city of Kolkata (India). Environ Monit Assess. 187:4206.

W. Shan, X. Jin, J. Ren, Y. Wang, Z. Xu, Y. Fan, Z. Gu, C. Hong, J. Lin, and Y. Zhou.,2019.Ecological environment quality assessment based on remote sensing data for land consolidation," J. Cleaner Prod., vol. 239, Art. No. 118126.

Wang, Y., Gong, H.L., Li, X.J., 2008. Monitoring and analysis of beijing ecological environment quality based on GIS. Remote Sens. Land Resour. 20, 91-96.

Wheeler, B.W., Lovell, R., Higgins, S.L., White, M.P., Alcock, I., Osborne, N.J., Husk, K., Sabel, C.E., Depledge, M.H., 2015. Beyond green space: an ecological study of population general health and indicators of natural environment type and quality. Int. J. Health Geogr. 14, 1-17.

Xisheng, H., Hanqiu, X., 2018. A new remote sensing index for assessing the spatial heterogeneity in urban ecological quality: A case from Fuzhou City, China. Ecological Indicators. 89, 11-12.

Xu, H., Ding, F., Wen, X., 2009. Urban expansion and heat island dynamics in the Quanzhou Region, China. IEEE J. Sel. Top. Appl. Earth Obs. Remote Sens. 2, 74-79.

Xu, H.Q., 2013a. Creation and application of urban remote sensing ecological index. Acta Ecol. Sinica. 33, 7853-7862.

Xu, H.Q., 2013b. Remote sensing evaluation index of regional ecological environment change. China Environ. Sci. 33, 889-897. 
643

644

645

646

647

648

649

650

651

652

653

654

655

656

657

658

659

660

661

Xu, H.Q.; Wang, M.Y.; Shi, T.T.; Guan, H.D.; Fang, C.Y.; Lin, Z.L. Prediction of ecological effects of potential population and impervious surface increases using a remote sensing based ecological index (RSEI). Ecol. Indic. 2018, 93, 730-740.

Y. Wang, X. Li, and J. Li, 2014. Study on the response of ecological capacity to land-use/cover change in Wuhan city: a remote sensing and GIS based approach. The Scientific World Journal, vol. 2014, Article ID 794323, 11.

Yue, H.; Liu, Y.; Li, Y.; Lu, Y., 2019. Eco-environmental quality assessment in China's 35 major cities based on remote sensing ecological index. IEEE Access.

Yunqing, J., Fei, Z., Yufeng, H., Hsiang-te, K., Verner Carl, J., Muhadaisi, A., 2020 Assessment of spatial and temporal variation of ecological environment quality in Ebinur Lake Wetland National Nature Reserve, Xinjiang, China. Ecological Indicators. 210. 105874.

Zhang, B.W., 2018. Eco-environmental quality evaluation and system design based on RSEI model. Zhengzhou University.

Zhang, J.Q., Zhu, Y.Q., Fan, F.L., 2016. Mapping and evaluation of landscape ecological status using geographic indices extracted from remote sensing imagery of the Pearl River Delta, China, between 1998 and 2008. Environ. Earth Sci. 75, 327-342.

Zhang, T.Y., Wang, L., Wang, H., Peng, L., Luo, C., 2017. Remote sensing monitoring of ecological environment in salinized irrigation areas of Manas river basin. Acta Ecol. Sinica 37, 30093018. 
Figures

\section{Study Area: Location Map}

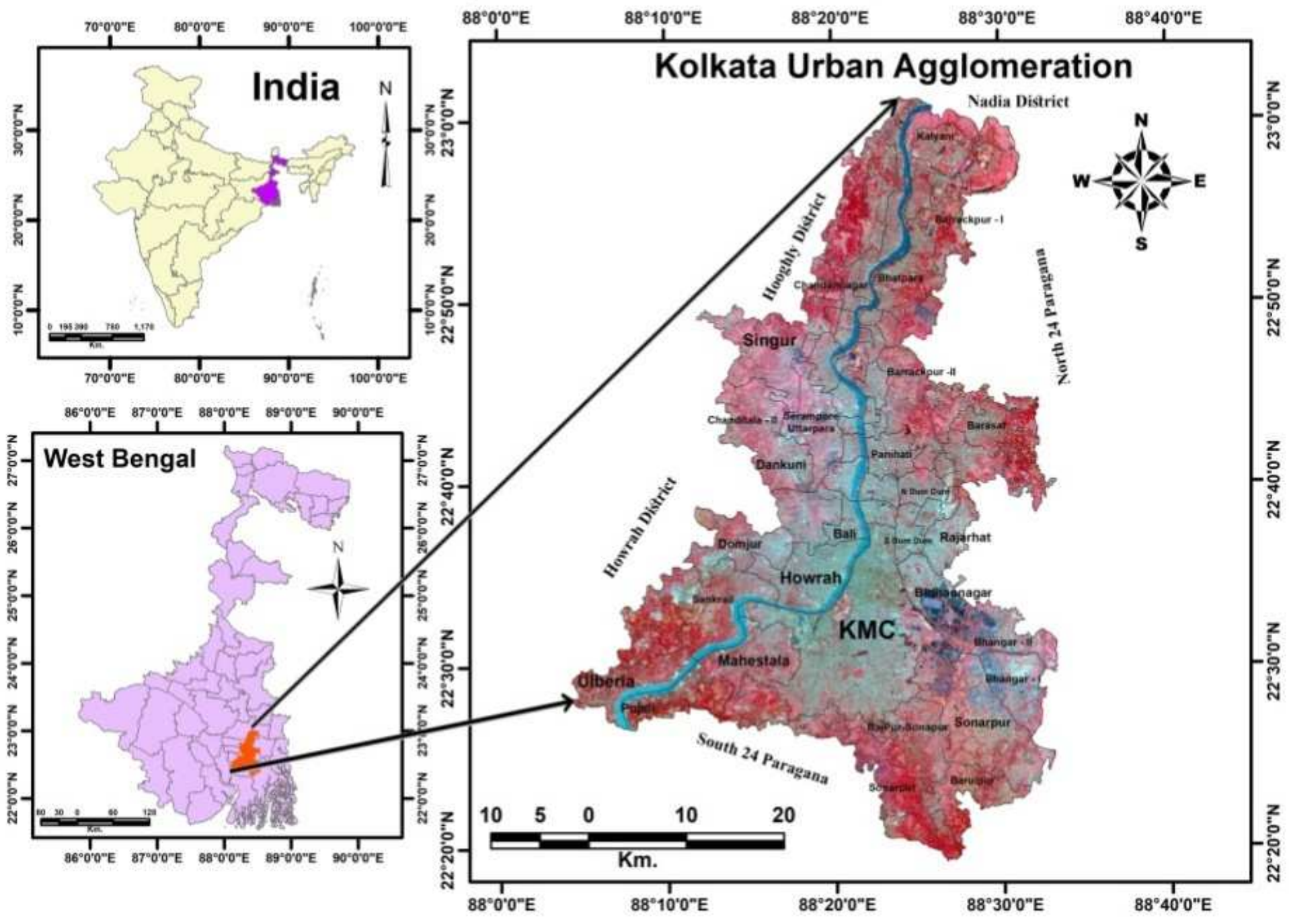

Figure 1

Map showing the location of KMA 


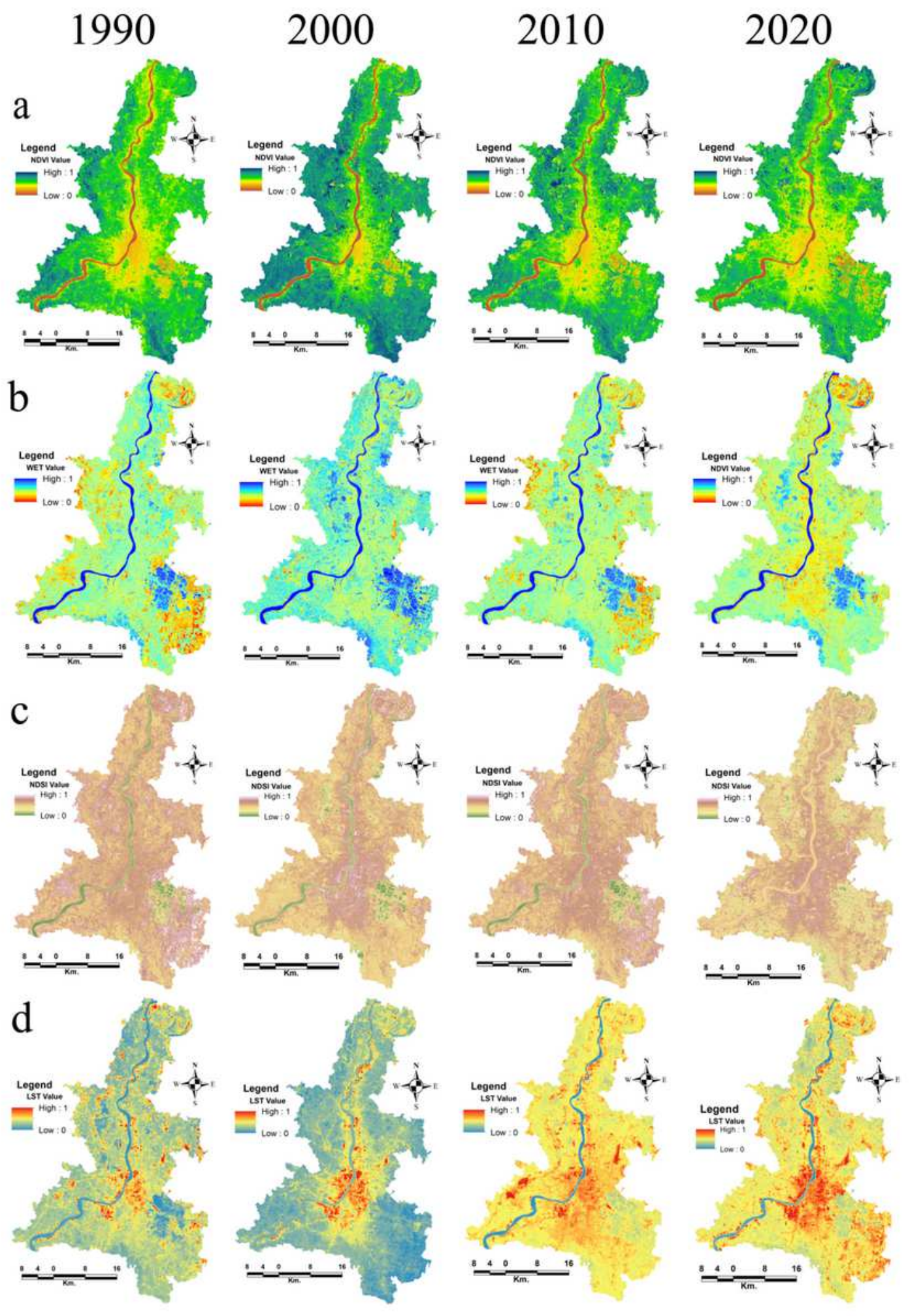

Figure 2

Spatio - temporal distribution of RSEl indices from 1990-2020 (a) NDVI, (b)WET, (c)NDSI and (d)LST 


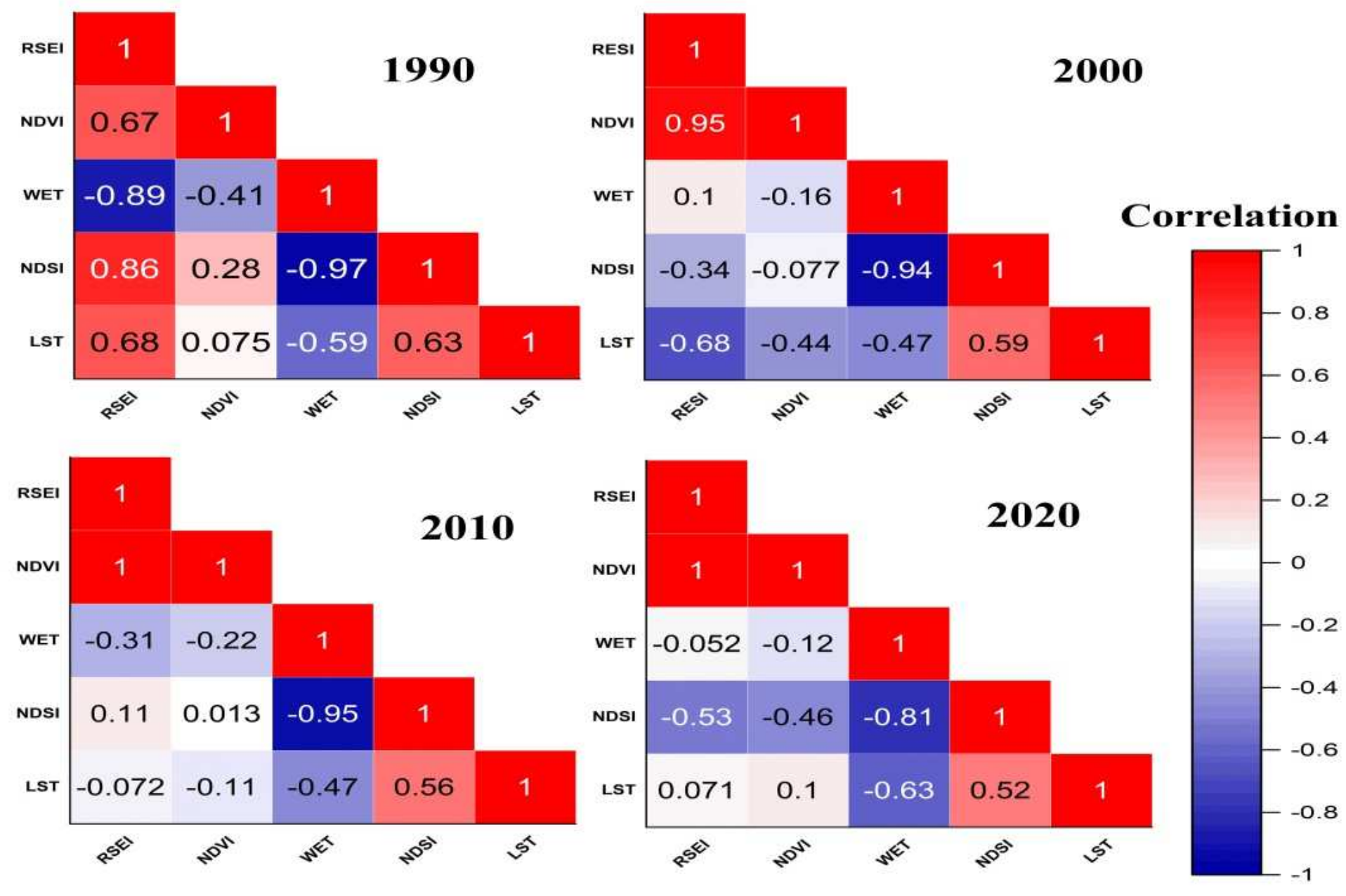

Figure 3

Correlation analysis of RESI and Four indicators 


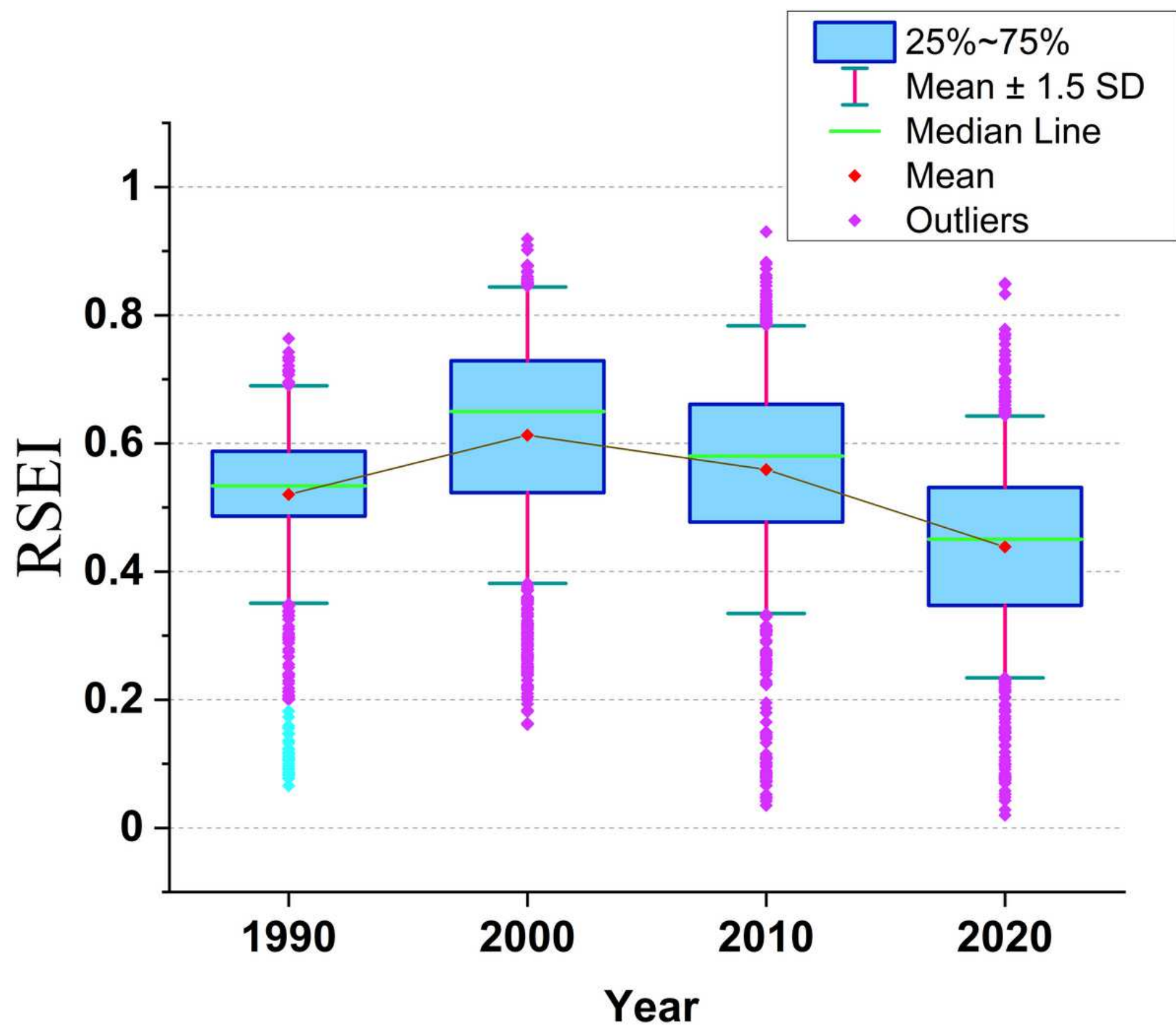

Figure 4

Change of RSEl in KMA in the year 1990, 2000, 2010 and 2020 
88*10'0"E

$8^{\circ} 20^{\circ} 0^{\prime \prime} E$

$88^{\circ} 30^{\circ} 0^{\prime \prime} \mathrm{E}$

$88^{\circ} 40^{\circ} 0$ " $E$

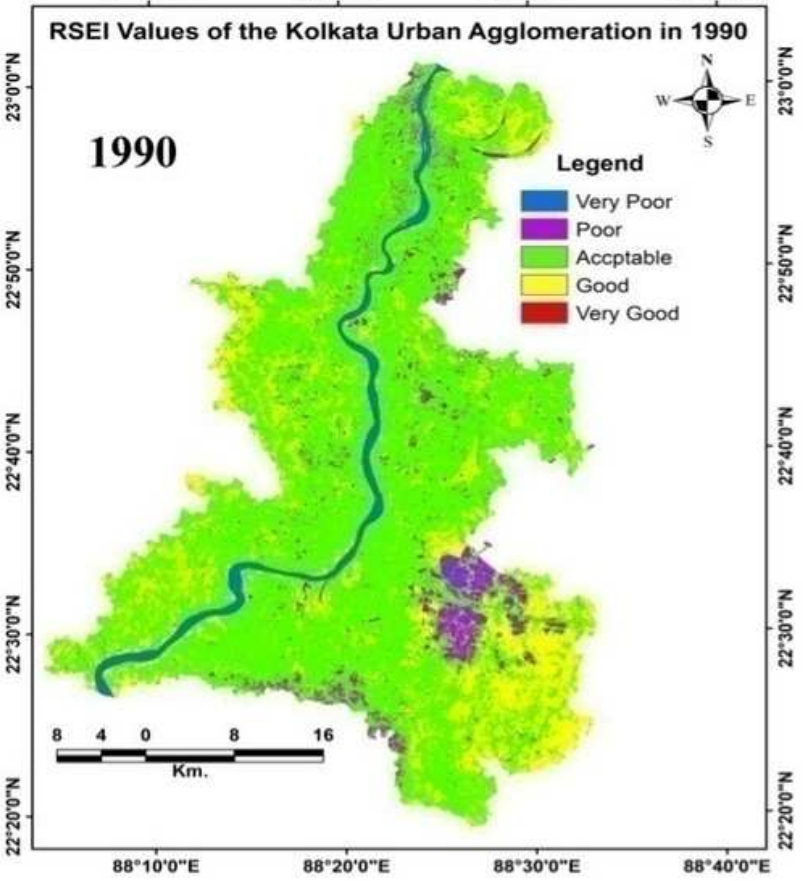

88.10.0"E 88.20'0"E $38^{\circ} 30^{\circ} 0^{\prime \prime} \mathrm{E}$ $88^{\circ} 40^{\circ} 0^{-1} \mathrm{E}$

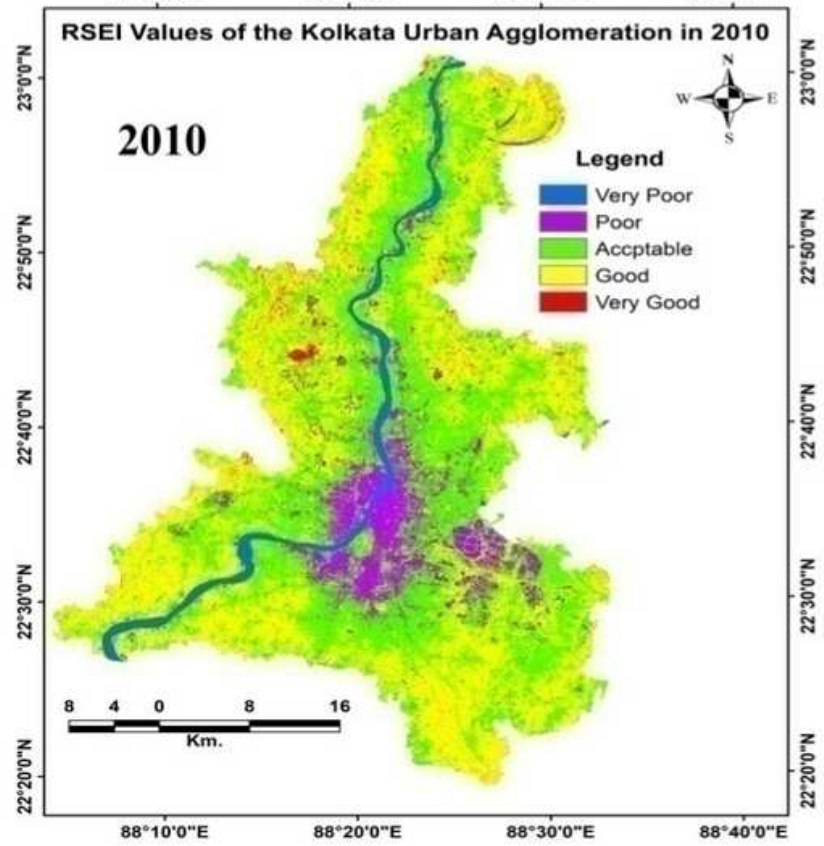

$88^{\circ} 10^{\prime} 0 " \mathrm{E}$

88*20'0"E

$88^{\circ} 30^{\prime} 0^{\prime \prime} E$

8840'0"E
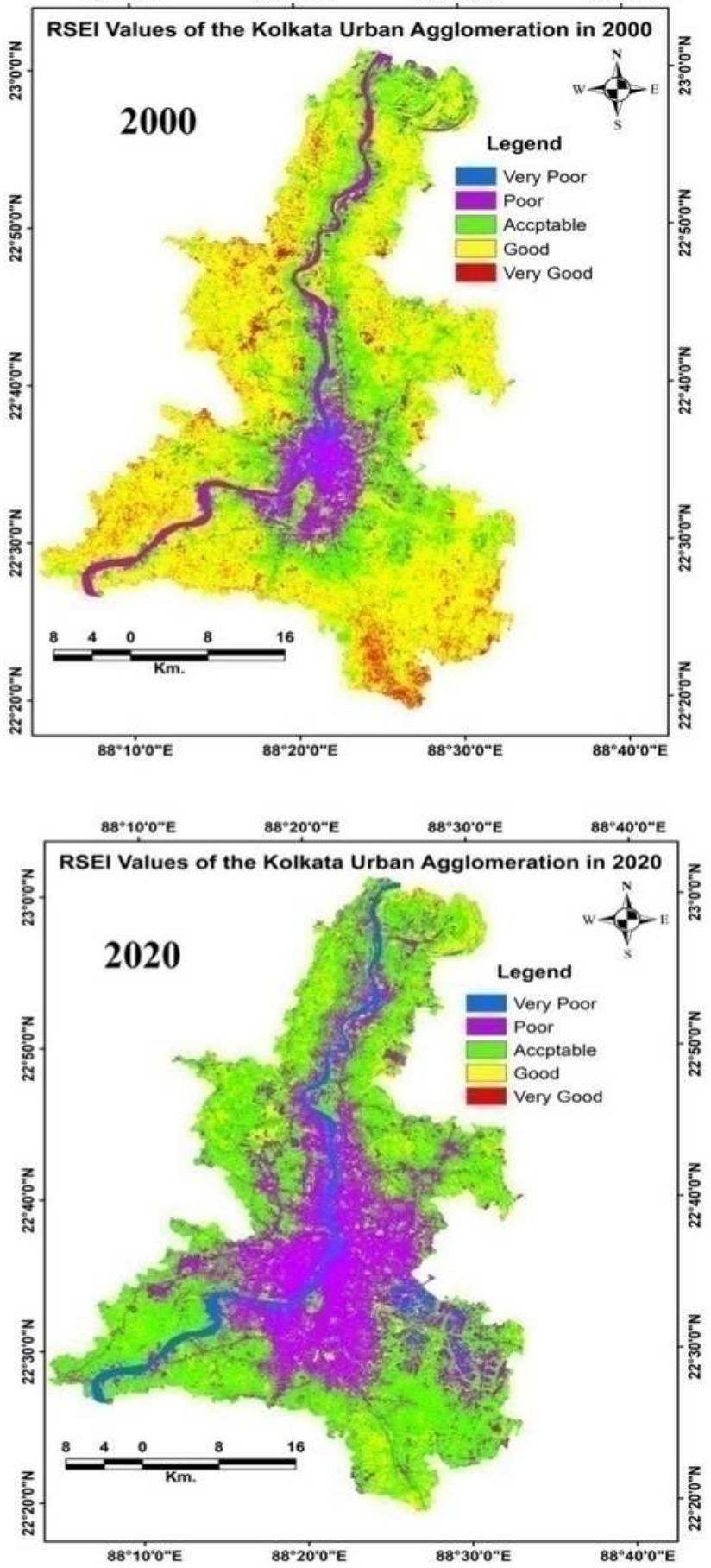

Figure 5

Spatio-temporal distribution of RSEl in KMA in the year 1990, 2000, 2010 and 2020 


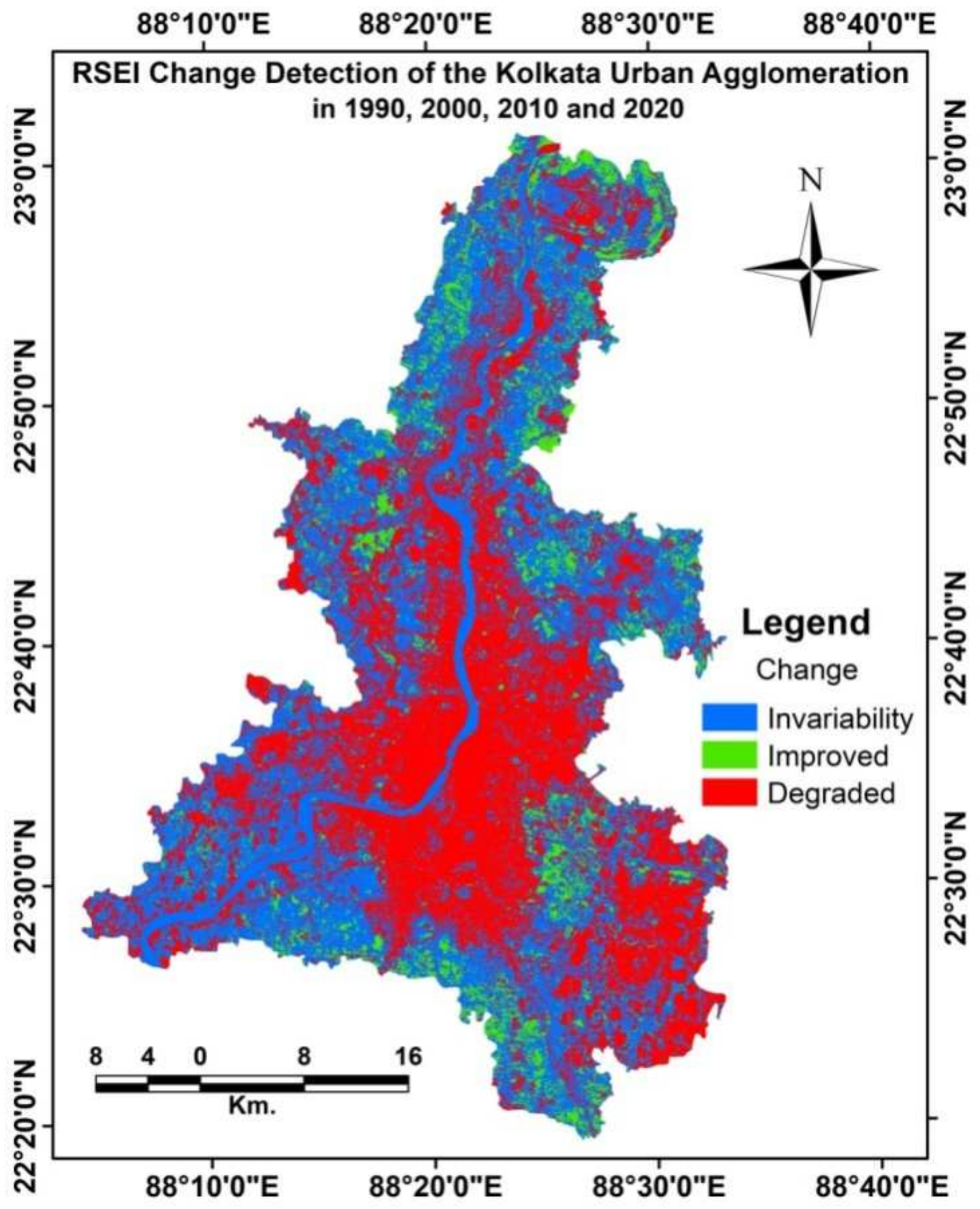

Figure 6

Remote sensing ecological index (RSEI) change detection of the Kolkata Urban Agglomeration 
Moran's I: 0.265

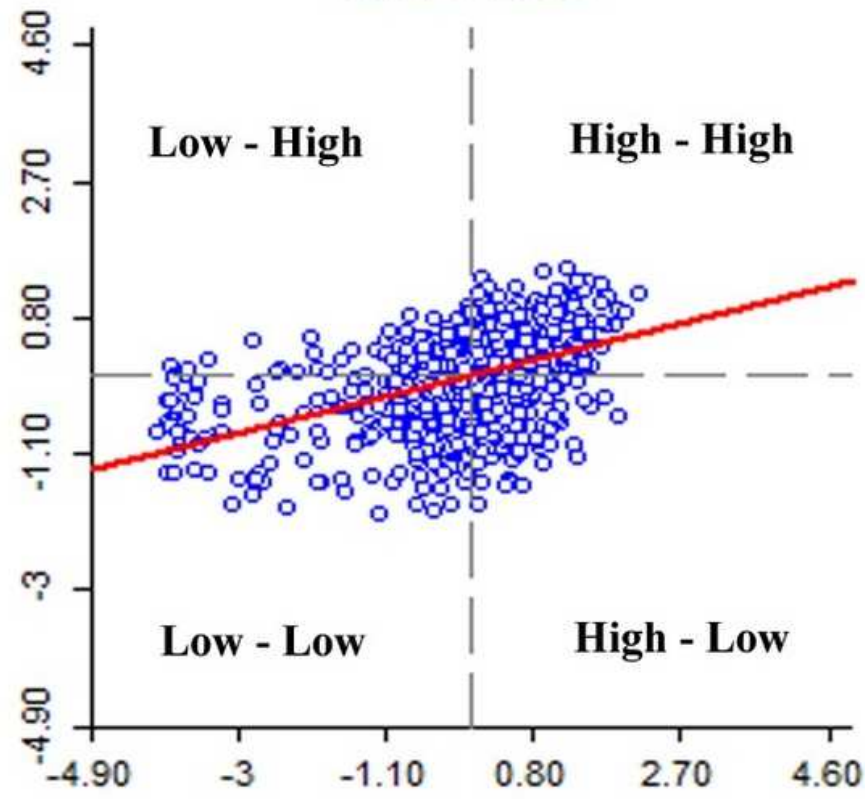

(a) 1990

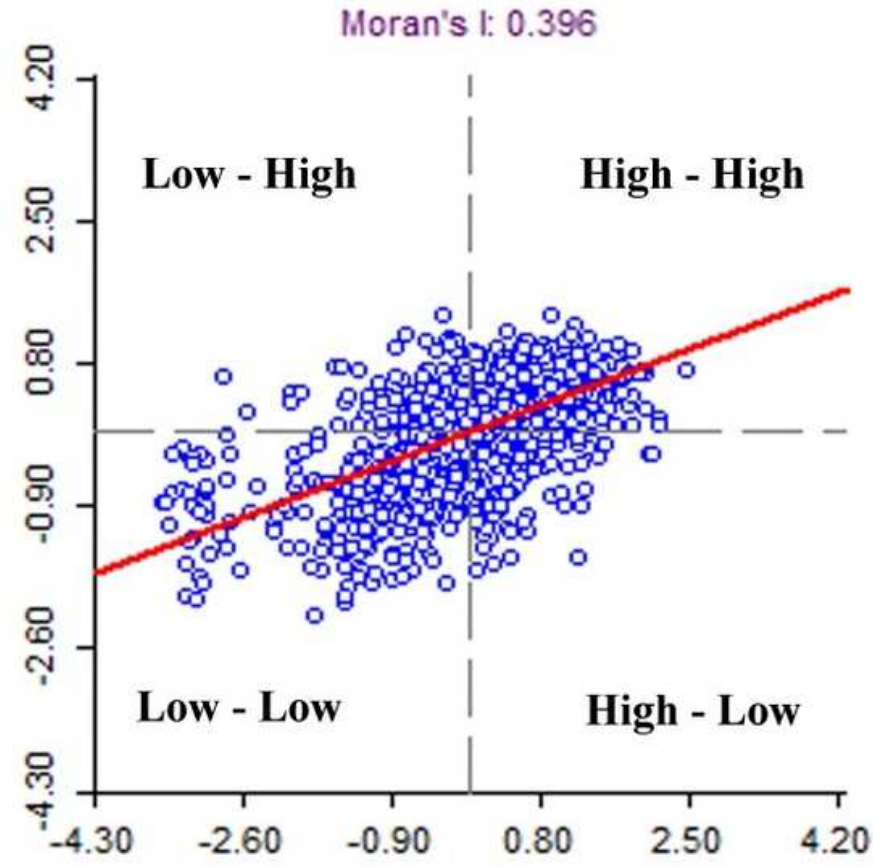

(c) 2010
Moran's I: 0.543

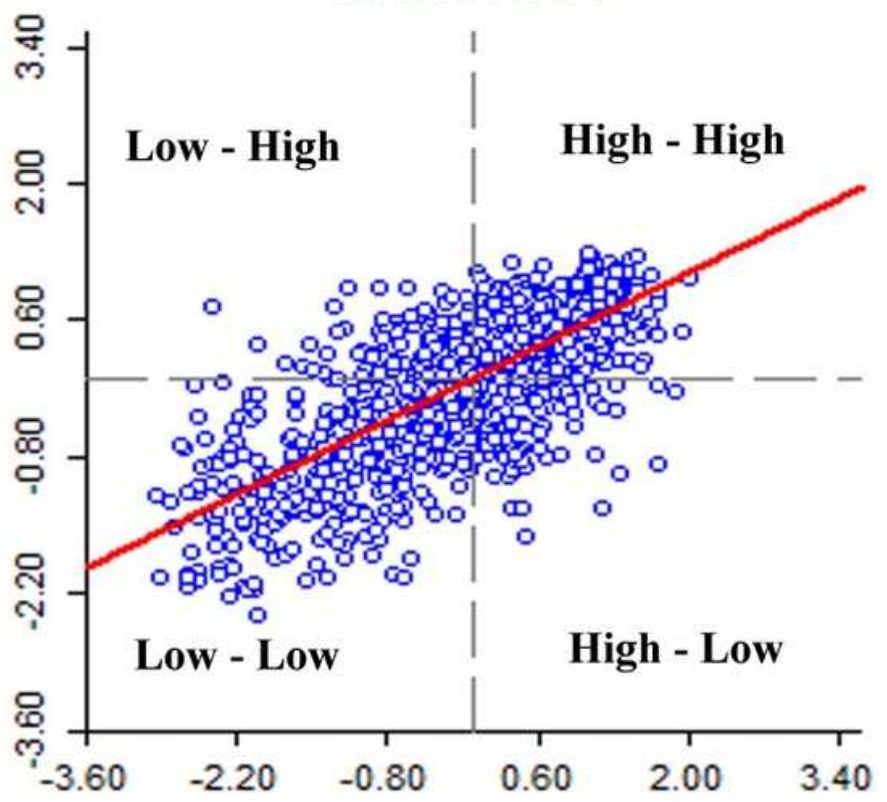

(b) 2000

Moran's I: 0.367

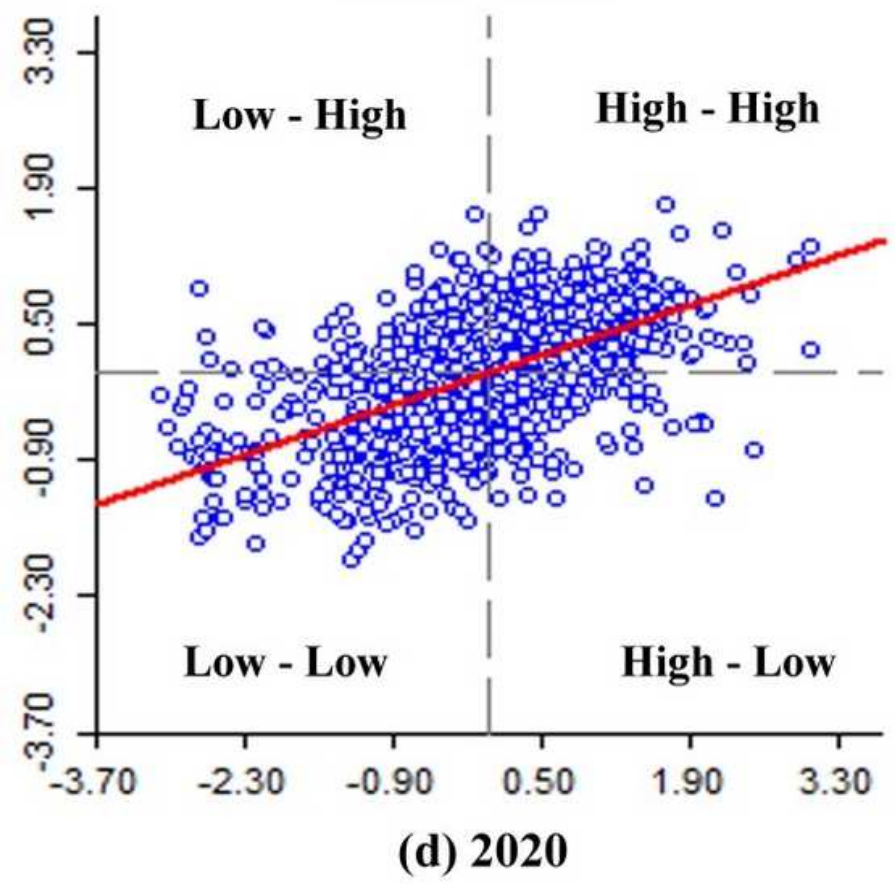

Figure 7

Moran's I scatter plot in the year of 1990, 2000, 2010 and 2020 

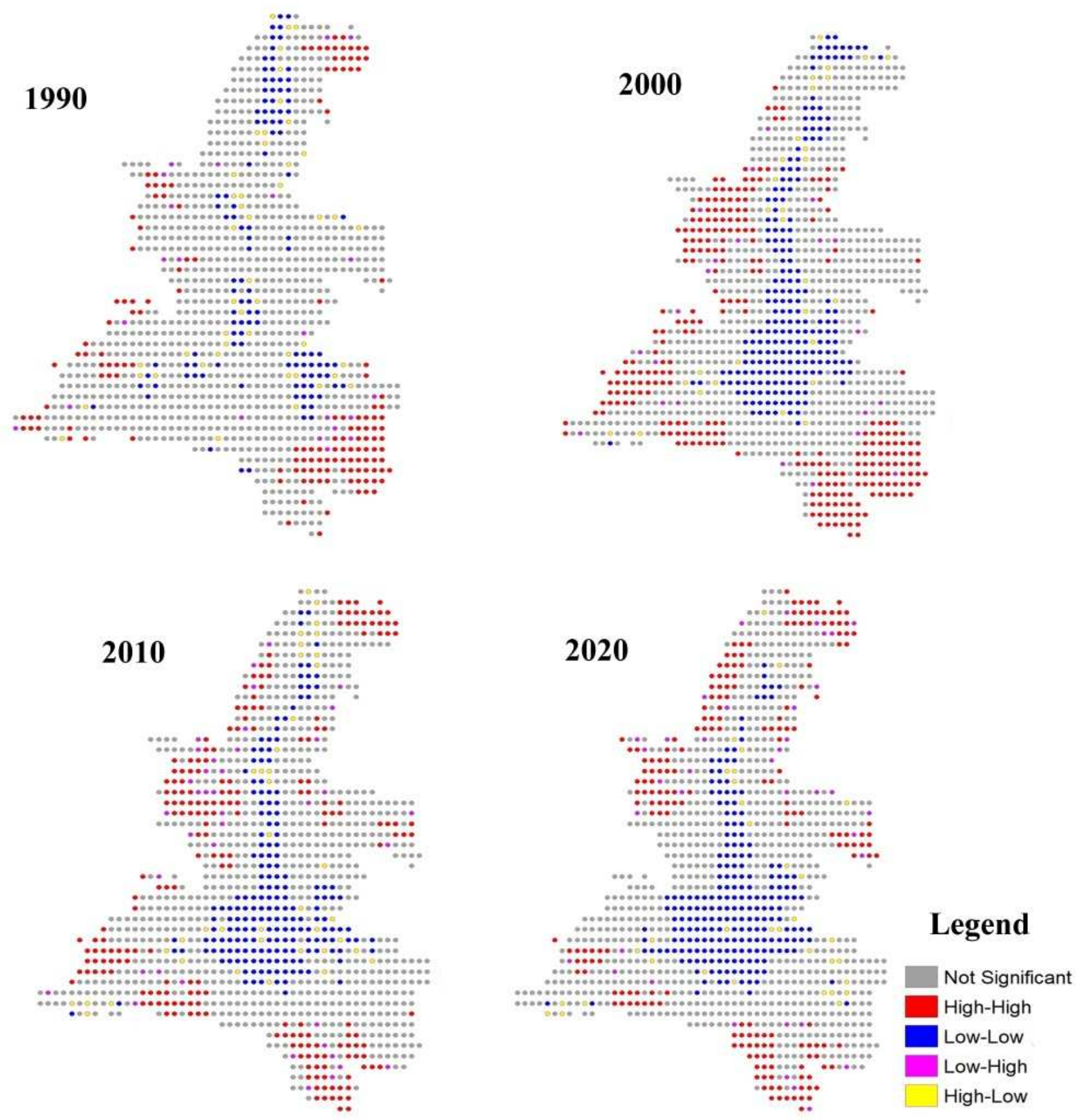

Figure 8

Local spatial auto-correlation (LISA) Cluster Map in Kolkata Urban Agglomeration in 1990, 2000, 2010 and 2020 

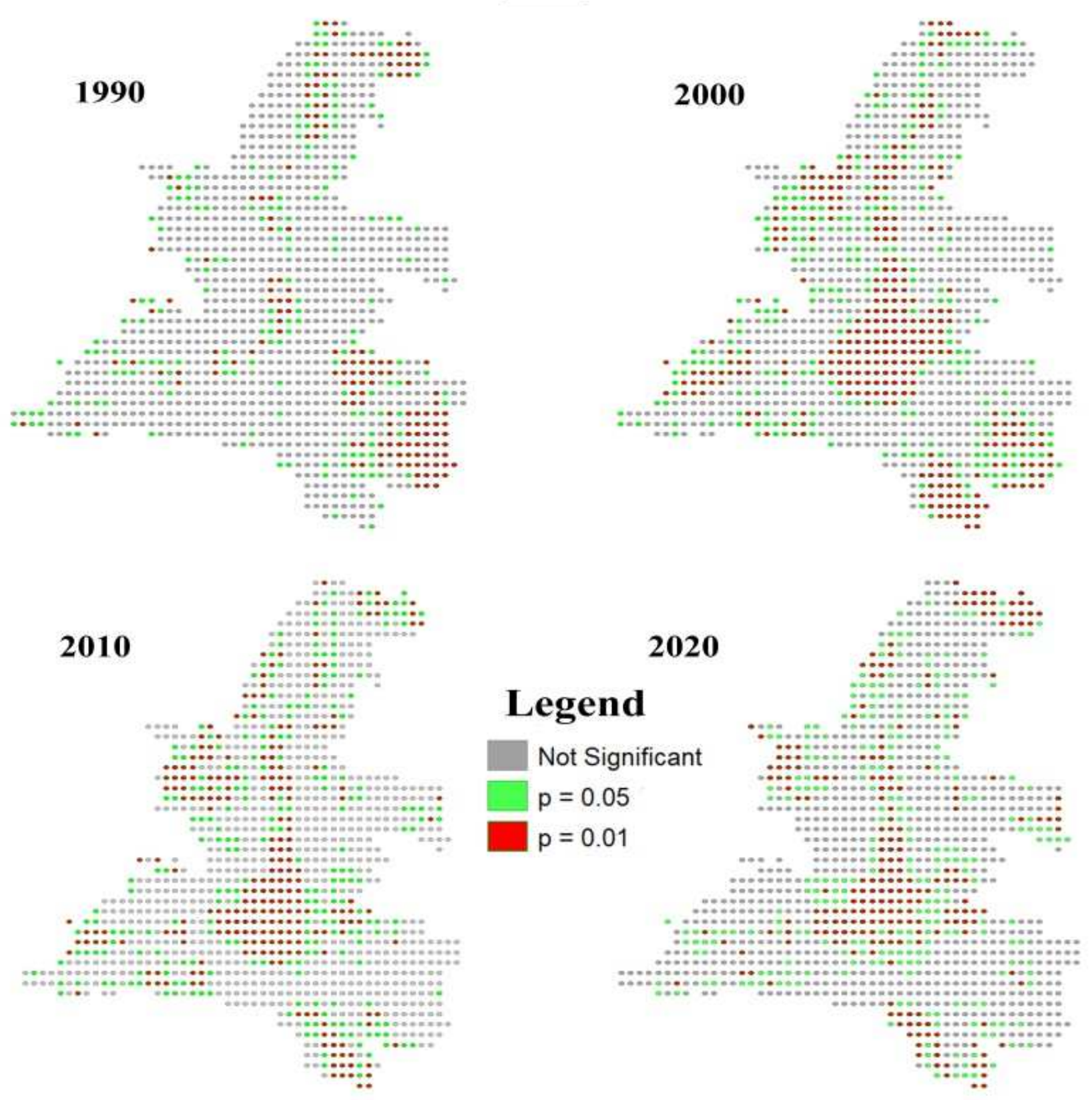

Figure 9

LISA significance Map in Kolkata Urban Agglomeration in 1990, 2000, 2010 and 2020
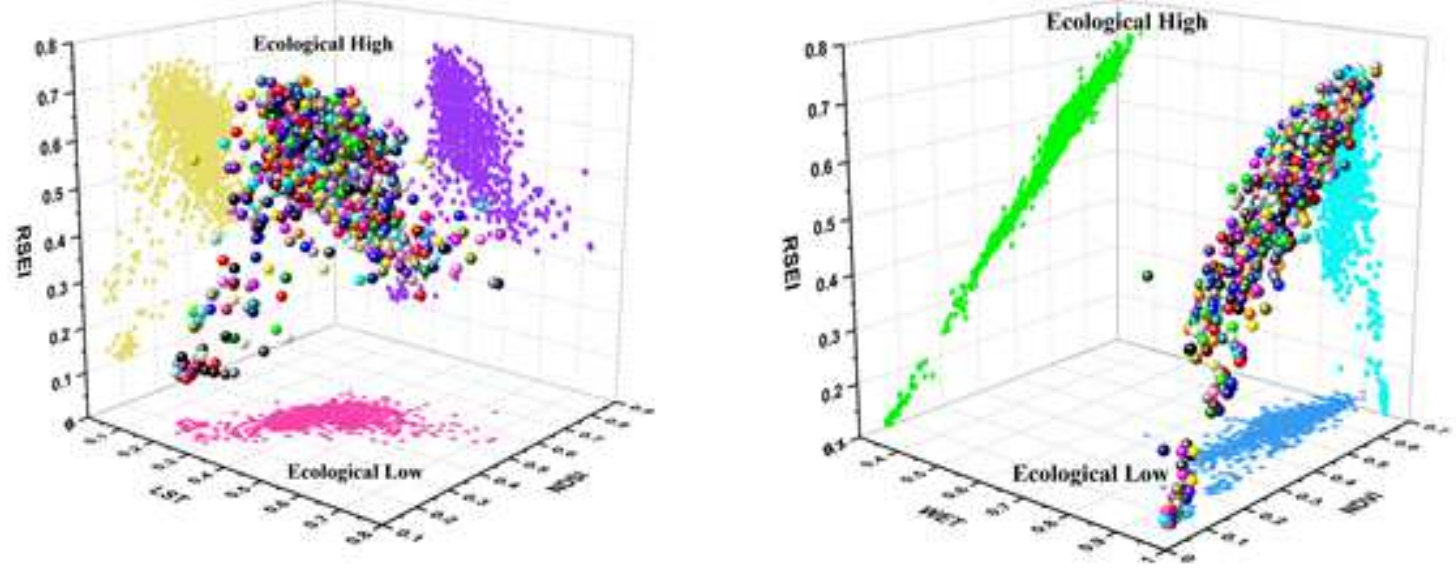
Figure 10

3D scatter plots of different indicators of RSEl in Kolkata Urban Agglomeration 